\title{
A contribuição de Max Weber para os estudos do jornalismo: um ensaio teórico- metodológico
}

\section{Virginia Pradelina da Silveira Fonseca}

Doutora; Universidade Federal do Rio Grande do Sul

vpradelina@uol.com.br

\section{Taís Seibt}

Doutoranda; Universidade Federal do Rio Grande do Sul seibt.tais@gmail.com

\section{Resumo}

Neste artigo, nosso objetivo é discutir a pertinência de alguns conceitos e da metodologia compreensiva de Max Weber para os estudos do Jornalismo enquanto uma instituição constitutiva da estrutura social. Para isso, primeiramente, retoma-se o conceito de ação social e sua respectiva tipologia, para, a seguir, discutir a possibilidade de conceber o jornalismo como uma ação social racional conforme os fins e conforme os valores. Dessa discussão, resulta a proposição de um novo paradigma para o estudo do jornalismo, que se está chamando, ainda provisoriamente, de "jornalismo de conhecimento".

\section{Palavras-chave}

Jornalismo. Ação social racional. Max Weber. Jornalismo de conhecimento.

\section{Introdução}

0 jornalismo é uma instituição ${ }^{1}$ à qual compete cumprir determinadas funções na estrutura social. Essas funções são o resultado das ações dos indivíduos que pertencem à instituição na sua relação com as outras pessoas da sociedade.

Em sociologia, o conceito de estrutura refere-se ao fato de que os contextos sociais não consistem em variedades aleatórias de acontecimentos ou ações, mas que são estruturados, ou padronizados, de distintas maneiras. "Existem regularidades na maneira 
como agimos e nas relações que temos uns com os outros", explica Giddens (2012, p. 21). "Considera-se uma estrutura social a ligação das partes que compõem o todo, o arranjo no qual os elementos da vida social estão ligados", complementam Cardoso e Ianni (1973, p. $35)$.

Por se referir às sociedades humanas, elas não são fixas. Do contrário, estão sempre em processo de estruturação. "Seus componentes básicos (seres humanos [...]) as reconstroem a cada momento" (GIDDENS, 2012, p. 21). Estrutura é, assim, a forma como a sociedade se organiza, e o conceito é um recurso analítico utilizado para compreender como as pessoas se comportam socialmente.

Como a estrutura social é marcada não apenas pelas ações humanas, mas, também, pelas instituições, o jornalismo é parte constitutiva desta, em relação a qual existem expectativas. No entanto, ao mesmo tempo em que se espera que cumpra uma determinada finalidade, também as mesmas são continuamente alteradas pelos atores sociais de alguma forma nela engajados.

Ao conceber o jornalismo como uma instituição da estrutura social, temos de refletir sobre sua função social - a relação entre uma ação social e o sistema no qual está inserida. "A função social é dada pelo resultado (consequência ou expectativa) da ação de um indivíduo (comportamento) em relação às outras pessoas que fazem parte de uma sociedade." (RIBEIRO, 2015).

Sob a perspectiva weberiana, esses conceitos (de estrutura, função e instituições sociais) são importantes para a compreensão da realidade social sempre que se tentar apreender as características dominantes e as peculiaridades de cada época e de cada contexto. Ante esses pressupostos, o que se ensaia neste texto é uma tentativa de compreender o jornalismo como uma ação social racional, uma vez que se trata de ato humano dotado de sentidos e finalidades, que criam e recriam regularidades na estrutura da sociedade.

\section{Objeto da sociologia weberiana: a ação social}

Max Weber é considerado um dos fundadores da ciência da sociedade, juntamente com Emile Dürkheim e Karl Marx. É um clássico, portanto, razão suficiente para ser retomado. Como lembra Giddens (2012), vive-se um período de transformação global que provavelmente seja tão profundo e sentido que precisamos de novas teorias para entender e 
explicar os novos acontecimentos. No entanto, anota o mesmo sociólogo, isso não significa que se deva abandonar totalmente as antigas perspectivas teóricas:

O que provavelmente será mais produtivo é colocar as velhas perspectivas em contato com as novas, para testar e comparar sua efetividade para nos ajudar a entender e explicar as mudanças dramáticas que estamos vivenciando (GIDDENS, 2012, p. 85).

Para o sociólogo alemão que, à semelhança de Durkheim e Marx, viveu em um período histórico marcado por profundas transformações na Europa, o objeto da Sociologia deve ser a ação social. Para ele, a sociologia é "uma ciência que pretende compreender interpretativamente a ação social e assim explicá-la causalmente em seu curso e em seus efeitos" (WEBER, 2014, p. 3). Isso seria possível mediante a observação das regularidades que se expressam na forma de usos, de costumes ou de situações de interesse. 0 conceito de ação social é, portanto, um dos mais importantes da sociologia compreensiva².

Por "ação" entende-se [...] um comportamento humano (tanto faz tratar-se de um fazer interno ou externo, de omitir ou permitir) sempre que e na medida em que o agente ou os agentes o relacionem com um sentido subjetivo. Ação "social", por sua vez, significa uma ação que, quanto a seu sentido visado pelo agente ou os agentes, se refere ao comportamento de outros, orientando-se por este em seu curso (WEBER, 2014, p. 3, grifos do autor).

A explicação sociológica, assim, visaria compreender o sentido, o desenvolvimento e os efeitos da conduta de um ou mais indivíduos em relação à do outro, ou seja, compreender o seu caráter social. Nessa ótica, como explica Kuschik (2006, p. 26),

A sociologia se aproxima da semiótica, em sua busca para entender os significados e os sentidos que estão associados aos signos. No caso da sociologia, uma atividade dirigida à interpretação das ações dos indivíduos na sociedade.

Considerado um dos intérpretes mais rigorosos do desenvolvimento histórico ocidental, visto como uma marcha da racionalidade, Weber acreditava que as condutas são tanto mais racionalizadas quanto menor for a submissão dos agentes aos costumes e afetos, e quanto mais se orientarem por um planejamento adequado à situação. "Pode-se dizer, [...] que as ações serão tanto mais previsíveis quanto mais racionais." (BARBOSA; QUINTANEIRO, 1999, p. 107).

Para compreender tais ações, o sociólogo alemão constrói um modelo de desenvolvimento da conduta racional: os tipos ideias, ou tipos puros; uma estratégia 
teórico-metodológica que lhe permite interpretar conexões de sentido na análise das condutas (ação social) tipificando-as, construindo modelos em relação aos quais pode observar eventuais desvios. 0 tipo ideal é um método, um instrumento de análise que permite a criação de tipologias puras. É um recurso baseado em conceitos, como religião, burocracia, capitalismo e, por conseguinte, jornalismo.

Uma das características do tipo ideal é o fato de que o modelo construído não corresponde à realidade, mas contribui para a sua compreensão. Ao delineá-los, o próprio autor adverte que os tipos 'puros' ('ideais'), "precisamente por isso, talvez sejam tão pouco frequentes na realidade quanto uma reação física calculada sob o pressuposto de um espaço absolutamente vazio" (WEBER, 2014, p. 12). Trata-se de um conceito teórico, abstrato, racional, criado com base nas escolhas pessoais daquele que analisa (realidade-indução), que serve como um guia na variedade de fenômenos que ocorrem na realidade. É, assim, uma forma de compreender a realidade sem de fato corresponder a ela, já que a realidade não é alcançável em sua totalidade pelo cientista, assim como não o são a neutralidade e a objetividade, como explica seu intéprete:

Nesses termos, [...], para poder esclarecer os fins a que se propõem, os indivíduos vão construir tipos-ideais, mediante atos, uma espécie de possível previsão em termos de conduta que subtrai os elementos irracionais da atividade e projeta como o sujeito realizaria a sua ação em termos ótimos (KUSCHIK, 2006, p. 26).

Isto considerado, o jornalismo pode ser compreendido como um tipo de ação social, que pode ser descrita como racional e ter o seu sentido interpretado através da construção de um modelo teórico elaborado com base nas características que apresenta a partir do final do século XIX, período a partir do qual passa a ser tido como um serviço de utilidade pública. É com esse (propósito), segundo a ideologia profissional, que as notícias são selecionadas dentre os acontecimentos de atualidade revestidos de relevância e interesse público. Esses sentidos permitem ao jornalismo se autolegitimar frente à sociedade como uma instituição nas democracias e, também, como uma profissão - uma vez que divulga e põe em circulação informações e ideias consideradas importantes e necessárias para que o leitor-cidadão tome decisões de forma esclarecida.

Ao criar os tipos ideais para compreender os sentidos das ações na esfera social, Max Weber (2014) constrói quatro tipos puros de ação social. São eles: a ação racional referente a fins, a ação racional referente a valores, a ação tradicional e a ação afetiva. 
Conforme explicam Barbosa e Quintaneiro (1999), pela tipologia weberiana, a ação de um indivíduo ou de um grupo seria racional em relação aos fins se, para atingir um objetivo previamente definido, lançasse mão dos meios necessários ou adequados para isso, avaliados tão claramente quanto possível do seu ponto de vista. A ação é considerada racional, portanto, se o agente persegue o objetivo pretendido recorrendo aos recursos disponíveis.

Será racional em relação a valores, por outro lado, se, ao perseguir seus fins, o agente orienta-se e age de acordo com ou a serviço de suas próprias conviç̧ões, levando em conta sua fidelidade a determinados valores, os quais seriam os verdadeiros inspiradores da sua conduta. Nesse caso, o agente cumpre um dever, um imperativo ditado por seu senso de dignidade, suas crenças, seus valores morais. Ele não é guiado pela consideração dos efeitos que advirão do seu padrão de conduta. Desse tipo de procedimento, resulta que a ação contenha algo de irracional. "O sentido da ação não se encontra, [...], em seu resultado, nas suas consequências, mas na própria conduta." (BARBOSA; QUINTANEIRO, 1999, p. 108).

Já a ação afetiva seria aquela inspirada em emoções imediatas (vingança, desespero, admiração, orgulho), sem a consideração de meios ou de fins a atingir. Distingue-se da racional orientada por valores pelo fato de que, nesta, o sujeito elabora conscientemente os pontos de direção últimos da atividade e se orienta em relação a eles racionalmente.

Por fim, a ação tradiconal tipificada por Max Weber corresponde a hábitos e costumes arraigados que levam à ação em função deles ("como sempre se fez"). Esse seria o caso, por exemplo, do batismo dos filhos quando realizado por pais pouco comprometidos com a religião. A ação estritamente tradicional, assim como a estritamente afetiva, encontrar-seiam no limite ou além do que o sociólogo considera ação orientada de maneira significativamente consciente, racional.

Conforme explicam Barbosa e Quintaneiro,

As combinações entre a maior ou a menor nitidez com que o indivíduo percebe suas próprias finalidades, os meios de que deverá servir-se para alcançá-las, assim como as consequências daí advindas, tornam necessária uma escala classificatória das condutas, que vai desde a racionalidade mais pura até a irracionalidade. 0 sociólogo capta intelectualmente, as conexões de sentido racionais, as que alcançam o grau máximo de evidência. Isso não ocorre com a mesma facilidade quando valores e afetos interferem nas ações. Nesses casos, a explicação sociológica encontra limites (BARBOSA; QUINTANEIRO, 1999, p. 107).

Ante essa tipologia, acredita-se que o jornalismo possa ser circunscrito a duas categorias de ação racional, concomitantemente: conforme os fins e conforme os valores. 


\title{
2 Jornalismo: ação social racional
}

A imprensa era objeto da atenção de Weber já no início do século XX, quando o sociólogo chegou a propor um programa de pesquisa que levasse em conta a crescente influência dos anunciantes sobre os jornais ${ }^{3}$. Nesse texto, de 1910, o autor diz que o fundamental para toda a discussão é o fato de que, 'hoje em dia', a imprensa é necessariamente uma empresa capitalista e privada, e que, ao mesmo tempo, ocupa uma posição totalmente peculiar - já que, ao contrário de qualquer empresa, tem dois tipos completamente diferentes de "clientes": os compradores de jornal e os anunciantes. Como explica Kuschik (2006), o sociólogo percebe o jornalismo como parte de um fenômeno de ação racional com relação a fins à medida em que sua atuação está delimitada pela aparição e distinção entre o público e o privado. Essa discriminação seria, para Weber, um claro exemplo da modernidade, pois,

\begin{abstract}
ao contrário do que sucedia 150 anos antes, quando os jornalistas tinham que pedir perdão aos membros do Parlamento Britânico por levar ao conhecimento público os debates que ali se realizavam, no início do século $\mathrm{XX}$ a imprensa era capaz de colocar os membros da classe de joelhos ao negar-se a publicar parte de seus discursos no Congresso (KUSCHICK, 2006, p. 30).
\end{abstract}

Desde esse ponto de vista, o jornalismo é, então, uma ação racional em relação a fins, porque, historicamente, foi estruturado enquanto organização privada capitalista condição plenamente configurada no século XXI, quando é apenas uma parte da ampla variedade de produtos culturais ofertados pelos conglomerados de comunicação (que atuam nos ramos da informação, do entretenimento e da prestação de serviços, entre outros). Como nos lembra Kuschik (2006), os jornais são entes que se enfrentam no mercado capitalista como entidades que buscam utilidade à semelhança de qualquer negócio ou atividade comercial. Além disso, a racionalidade e a lógica do capitalismo se impõem em uma atividade cuja mercadoria são as notícias, as críticas e os comentários sobre a atividade política a partir de uma concepção político-ideológica. Em pesquisa realizada nos primeiros anos do presente século (FONSECA, 2008), acredita-se tê-lo demonstrado fartamente, de modo que se pode afirmar que a ação das empresas que têm o jornalismo como negócio é do tipo racional com relação aos fins - têm objetivos claramente definidos, que são perseguidos mobilizando-se os recursos necessários para os atingir.

Entretanto, o jornalismo não é puramente um negócio. Ao se tornar uma profissão, estrutura-se, também, em torno de valores. Os jornalistas que produzem as notícias

3 Ver: WEBER, Max. Sociologia da imprensa: um programa de pesquisa. In: MAROCCO, Beatriz; BERGER, Christa. (Orgs.). A era glacial do Jornalismo: teorias sociais da imprensa. Porto Alegre: Sulina, 2006. p. 34-44 
(mercadoria) para as empresas capitalistas compartilham valores próprios, crenças expressas numa cultura e numa deontologia profissional, como são exemplos o dever de verdade (um imperativo categórico) e os ideais de objetividade ${ }^{4}$, de isenção e de seleção das notícias a critério do interesse público. Tais valores podem ser exemplificados por este trecho transcrito de livro que trata de ética jornalística:

[Em relação ao jornalismo] Seu objetivo primordial não é difundir aquilo que governos, igrejas, grupos econômicos ou políticos desejam contar ao público, embora também se sirva disso, mas aquilo que o cidadão quer e tem o direito de saber, o que não necessariamente coincide com o que os outros querem contar (BUCCI, 2000, p. 42).

Ou com trechos do Código de Ética adotado pela Society of Professional Journalists (SPJ), entidade norte-americana para quem é dever do jornalista: buscar e relatar a verdade, minimizar os danos, agir com independência e responsabilizar-se por suas ações. Os valores, como lembra Williams, servem de critérios para a seleção da ação, e se tornam critérios para o juízo, a preferência e a escolha (WILLIAMS, 1979 apud PLAISANCE, 2011, p. 51).

Com isso, pode-se dizer que o jornalismo é também uma ação racional em relação a valores. Conforme atesta Kuschick (2006):

Apesar de pertencer a uma empresa capitalista, que sobrevive apenas se vende jornais, os jornalistas têm a crítica como o seu meio de expressão e essa pode se dar somente em função de critérios, ideais, utopias e imagens do mundo aos quais estão associados tanto os articulistas dos jornais como os políticos e o público (p. 30).

0 próprio Weber, ao propor uma concepção de ética que combina convicção e responsabilidade, dá oferece elementos para sustentar a ideia de que o jornalismo é uma ação racional também em relação a princípios. Em 1919, em uma de suas mais importantes conferências ${ }^{5}$, o sociólogo situa o jornalismo no âmbito privilegiado do fazer político, e apresenta os conceitosde ética da convicção e ética da responsabilidadé ${ }^{6}$ Segundo ele, a ação ética do homem moderno deve combinar convicção e responsabilidade, obrigatoriamente, pois que não seriam excludentes, mas complementares e, juntas, moldariam o homem autêntico (WEBER, 2000 apud COSTA, 2009).

\footnotetext{
4 Por objetividade jornalística, entende-se "O sistema de regras que tem como objetivo a produção de uma semelhança estrutural entre realidade social e realidade midiática," (SPONHOLZ, 2009, p. 17).

5 A conferência foi traduzida para o português lusitano como "A política como profissão" e, no Brasil, como "A política como vocação".

$6 \mathrm{Na}$ formulação de Max Weber, a ética da convicção atribui aos valores uma vigência forte, um caráter absoluto. O agente age conforme suas convicções sem se importar com as consequências dos seus atos. Na ética da responsabilidade, o agente preocupa-se com as consequências dos seus atos.
} 


\section{A atualidade da contribuição de Weber}

A adoção de uma perspectiva teórico-metodológica weberiana decorre da convicção de que o jornalismo não é apenas um setor dos negócios das grandes corporações de mídia, embora se reconheça seu caráter de mercadoria e a lógica capitalista predominante nessas organizações. A caracterização do jornalismo enquanto ação racional conforme os fins e conforme os valores nos permite ampliar o olhar analítico para uma prática socialmente institucionalizada e legitimada pelo público como fonte de informação relevante nas sociedades democráticas.

Conforme explana Giddens (2012), Max Weber acreditava que os fatores econômicos eram importantes, mas que as ideias e os valores também tinham uma grande influência nas transformações sociais. "Argumentava que a sociologia devia se concentrar na ação social, e não em estruturas sociais." (GIDDENS, 2012, p. 28). Defendia que a motivação e as ideias humanas eram as forças por trás da mudança - que ideias, valores e opiniões tinham o poder de provocar mudanças.

Segundo Weber, os indivíduos têm a capacidade de agir livremente e de moldar o futuro. Ele não considerava, como Durkheim e Marx, que as estruturas existiam fora ou independentemente dos indivíduos. Pelo contrário, as estruturas da sociedade eram formadas por uma complexa inter-relação de ações. E era trabalho da sociologia entender os significados por trás dessas ações (GIDDENS, 2012, p. 28).

Por essa razão, julga-se relevante investigar tanto as mudanças estruturais nas organizações como as finalidades da instituição jornalismo na contemporaneidade. Mas também os valores dos indivíduos que, profissionalmente, as colocam em funcionamento.

A abordagem compreensiva implica a adoção de metodologia correspondente, ou seja, o acionamento do conceito de "tipos-ideais". Tais modelos conceituais e analíticos produzidos por Weber permitem entender e atribuir sentido às ações sociais, sempre tendo em vista que:

No mundo real, os tipos raramente, ou nunca, existem - muitas vezes apenas alguns dos seus atributos estão presentes. Todavia, essas construções hipotéticas podem ser muito proveitosas, pois é possível entender qualquer situação do mundo real comparando-a com um tipo ideal. Dessa forma, os tipos ideais servem como um ponto de referência fixo (GIDDENS, 2012, p. 29).

O sociólogo inglês anota, ainda, a importância de se mostrar que, com o tipo "ideal", Max Weber não desejava afirmar que a concepção era um objetivo perfeito ou desejável. "Ao 
invés disso, [....] queria dizer que era uma forma 'pura' de um certo fenômeno." (GIDDENS, 2012, p. 29).

O método referente foi utilizado por Brin, Charron e Bonville (2004) para elaborar uma periodização do jornalismo norte-americano de acordo os modelos predominantes em cada época. Os autores contam a história do jornalismo, desde os seus primórdios na América, em quatro períodos, aos quais corresponde um determinado modelo (ou paradigma, na acepção de Thomas Khun). Essa história seria constituída por períodos de relativa estabilidade pontuada por profundas transformações, o que autores como Castells (2000a) chamariam de "revolução".

Segundo eles, no primeiro período, no século XVII, os jornais eram feitos pelos impressores, que recolhiam, consignavam e difundiam nas suas gazetas as correspondências, os anúncios e outros conhecimentos que quisessem oferecer. Esses impressores agiam como um elo entre as fontes e os leitores. "Não há propriamente que falar de direito à palavra. [...] Nem o gazeteiro, nem o jornalista tem nessa época uma verdadeira identidade discursiva [...]" (BRIN; CHARRON; BONVILLE, 2004, s.p.). A esse período, dizem corresponder um modelo que chamam de "Jornalismo de Transmissão".

A esse se seguiria, no século XIX, um "Jornalismo de Opinião". Diante de um contexto de transformações das instituições políticas (debate sobre o voto, sistema partidário, etc.), o gazeteiro (dono da gazeta) se transforma em editor e põe o seu jornal a serviço das lutas políticas. Como as limitações tecnológicas e os altos índices de analfabetismo eram obstáculo para que se dirigissem ao grande público, as edições voltavam-se para as elites políticas. Financiado em parte pelos leitores, parte pelo mecenato e parte pela publicidade, o jornal caracteriza-se como uma folha modesta que não provia objetivos comerciais.

No terceiro período, predominaria o que chamam de um "Jornalismo de Informação", que emerge no final do século XIX no âmbito das mudanças comerciais que ampliam as possibilidades de transformação do jornalismo em negócio forte e lucrativo. Nessa fase, os empreendedores percebem que podem obter mais lucros se abandonarem o debate político, fonte de divisão da população, em favor de conteúdos que interessem a um público mais amplo. Esse modelo aparece nas grandes cidades americanas entre 1880 e 1910 e se generaliza a partir de 1920, quando se torna dominante. As condições técnicas, econômicas e de infraestrutura (estradas de ferro, telégrafo e telefone) possibilitam a produção e distribuição do jornal em larga escala, assim como a criação de uma rede de coleta de notícias de atualidade. Segundo os autores, a abordagem "profissional/cronocentrista" da 
história do jornalismo nos faz pensar que esse é o período do "verdadeiro jornalismo", aquele que conhecemos hoje e que teria surgido no final do século XIX como resultado de um movimento de profissionalização. Acredita-se ser possível dizer que esse é o período em que o jornalismo de autolegitima socialmente e em que se fortalecem os seus valores (crenças compartilhadas), tais como: independência, objetividade, verdade, isenção e interesse público -, cristalizados em códigos deontológicos mundo a fora.

Esse período, contudo, encontraria seus limites nas décadas de 1970 e 1980, quando uma fase de modificações começa a configurar um novo modelo - o "Jornalismo de Comunicação". Para os autores, o que distingue este do paradigma anterior é a preocupação de empresários e jornalistas com as preferências da audiência, processo que resultaria, segundo eles, da hiperconcorrência e da superabundância de mensagens, que leva os meios e os próprios profissionais da informação a buscarem formas de distinção entre si. Diríamos que a produção de conteúdos passa a ser regida, prioritariamente, pelo critério do gosto do público, em detrimento de valores que norteavam a conduta do profissional na fase anterior - como a concepção de que o jornalismo é um serviço de interesse público. Vale reproduzir um trecho do que observam os autores sobre isso:

Os jornalistas pregam mais abertamente sua subjetividade e tentam estabelecer com o público, cada vez mais segmentado, laços de conivência e de intersubjetividade. Os gêneros jornalísticos que dão amplo espaço ao comentário (crônicas opinativas, de humor e temáticas, cartas e mensagens dos leitores, etc.) estão em clara ascensão; a notícia, gênero por excelência do jornalismo de informação, incorpora mais e mais julgamentos e comentários (BRIN; CHARRON; BONVILLE, 2004, s.p7).

Nesse contexto, dizem, o hibridismo entre o discurso da imprensa e o de outras formas de discurso midiático é tolerado. De fato, encorajado: "a ficção se mistura à realidade, notícias banais adquirem o status de acontecimento, a informação se faz entretenimento e adota voluntariamente o tom do humor ou familiar da conversação; a efusão e a emoção têm lugar de explicação; o tom e o estilo do discurso promocional impregnam o discurso de imprensa" (BRIN; CHARRON, BONVILLE, 2004, s.p). ${ }^{8}$

A título de exemplo, pode-se dizer que a reforma gráfico-editorial feita em 2014 pelo jornal Zero Hora, pertencente ao Grupo RBS, é bastante ilustrativa do modelo descrito. Uma

\footnotetext{
7 Usa-se, como referência, um "manuscrito" preparado pelos tradutores para publicação da obra em português. Por isso, não há possibilidade de indicação da página de onde se retira o excerto.

8 Os autores advertem que essa periodização corresponde a um esquema narrativo que divide a história da imprensa norteamericana em quatro fases semelhantes às correspondentes aos quatro paradigmas jornalísticos. Essas etapas seriam modelos de desenvolvimento histórico e não constituiriam uma descrição sócio-histórica.
} 
das mudanças mais importantes se deu na disposição do conteúdo estritamente jornalístico: editorias tradicionais (como política, economia e geral) foram extintas em favor de uma organização que agrupa os seus conteúdos em uma única rubrica, intitulada "Notícias". 0 restante "do produto" que, outrora, acreditava-se ser integralmente um jornal (cuja razão de ser era a notícia) passou a ser composto por conteúdos produzidos para atender ao gosto da audiência: entretenimento, beleza, comportamento, moda, esportes, etc. Além disso, como também observa Néveu (2006), esse padrão se traduz pelo aumento das soft news ${ }^{9} \mathrm{e}$ da informação-serviço, assim como pelo declínio correlativo da cobertura internacional e da política, em um cenário em que se tem dificuldade em discernir entre jornalismo e outras modalidades de comunicação.

\section{Um paradigma diferencial: "Jornalismo de conhecimento"}

Diante de um contexto em que há dificuldade de se discernir o conteúdo jornalístico dos demais conteúdos veiculados nos meios de comunicação, é preciso que nos questionemos, afinal, o que os identifica. 0 que seria essencial para a temática jornalística e deveria ser perene, no sentido de sustentar o jornalismo enquanto instituição, diante das transformações que o mesmo atravessa e do avanço das tecnologias de comunicação no século XXI? Inspiradas na tipificação dos autores canadenses, propomos aqui, ensaisticamente, um paradigma diferencial do jornalismo, ao qual daremos o nome de "jornalismo de conhecimento".

Nossa hipótese tem origens no início do século XX, quando o jornalista e sociólogo Robert Park via, no surgimento da notícia - e do repórter -, um dos mais importantes eventos da civilização norte-americana. Park concebia a notícia como uma "forma social de conhecimento", cuja função seria "orientar" o indivíduo, preservando sua sanidade em uma sociedade que passava por mudanças "rápidas e drásticas" (MACHADO, 2005). 0 período entre-guerras, especialmente após a quebra da bolsa de valores de Wall Street, em 1929, provocou mudanças sociais intensas nos Estados Unidos. A derrocada do sistema capitalista norte-americano deixou muitas famílias sem emprego, sem comida e sem economias, pois até mesmo os bancos onde pretendiam sacar suas poupanças haviam falido. Complementarmente, o governo não tinha programas de seguridade social que pudessem garantir qualquer assistência à classe média que havia emergido economicamente ao longo

\footnotetext{
${ }^{9}$ Notícias sobre temas leves.
} 
do século XIX e via-se assombrada por uma situação de miséria aparentemente sem explicação.

Nesse contexto, os editores de jornais, assim como os manuais de jornalismo existentes na época, passaram a dar ênfase à "reportagem interpretativa". Uma das referências dessa natureza de abordagem advém do compêndio de jornalismo editado por Curtis MacDougall, publicado em 1932, com o título de "Reportagem para iniciantes" e reeditado em 1938, como "Reportagem interpretativa", no intuito de dar ênfase à "tendência inequívoca de combinar a função de intérprete com a de repórter" (SCHUDSON, 2010, p. 172). Anos antes, em 1933, a Sociedade Norte-americana de Editorias de Jornais já havia decidido que fosse um consenso entre os editores que os jornais devotassem mais espaço às notícias explicativas e interpretativas e apresentassem um histórico de informação que permitisse ao leitor médio compreender mais adequadamente o mecanismo e o significado dos eventos (SCHUDSON, 2010.

Robert Park percebeu nas transformações de então uma oportunidade de posicionar o jornalismo como elemento estruturante da sociedade, uma instituição que permaneceria enquanto outras eram alvo de desconfiança. Como resgata Elias Machado (2005, p. 29), enquanto alguns intelectuais viam o jornal como crime e o povo como espécie de tribuna, Park percebeu que o mais importante era identificar o jornal como "uma instituição social nascida para atender às demandas comunicativas de uma sociedade cada vez mais complexa". Para sustentar sua proposição de que a notícia é uma forma de conhecimento, Park se apropriou das noções de "conhecimento de" e "conhecimento acerca de", propostos por William James, em 1896. 0 conhecimento de é “[...] um tipo de conhecimento que alguém inevitavelmente adquire ao longo de seus encontros pessoais e de primeira mão com o mundo ao seu redor" (PARK, 2008, p. 52). É o conhecimento pessoal adquirido pelo indivíduo que se adapta ao mundo graças a uma fusão de experiências. Em contraste a esse conhecimento instintivo e intuitivo, há um conhecimento formal, racional e sistemático - o conhecimento acerca de. 0 caráter exclusivo desse conhecimento científico é que ele é comunicável, enquanto o senso comum, baseado na experiência prática, não o é.

As duas formas de conhecimento, no entanto, fazem parte de um continuum dentro do qual todos os tipos de conhecimento encontram lugar - e onde a notícia tem localização própria. Park afirma que a notícia não é conhecimento sistemático como a ciência física, pois trata de eventos, invariavelmente fixos no tempo e localizados no espaço. 
A notícia, como forma de conhecimento, primariamente não está interessada no passado ou no futuro, mas no presente - o que tem sido descrito pelos psicólogos de "o presente precioso". Pode-se dizer que a notícia existe somente nesse presente. 0 significado do "presente precioso" é sugerido aqui pelo fato de que a notícia, como é sabido pela imprensa comercial, é um produto muito perecível (PARK, 2008, p. 59).

A fragilidade da proposição de Park reside no fato de considerar que a notícia "[...] desempenha as mesmas funções para o público que a percepção desempenha para o indivíduo; isto é, não apenas informa, mas orienta." (PARK, 2008, p. 60). A compreensão do autor subentende que o tipo de conhecimento gerado pelo jornalismo não ultrapassaria o do senso comum, o que torna sua visão bastante criticável diante da emergência de reportagens interpretativas nas primeiras décadas do século XX. Parece que é nesse gênero, e não na notícia como "flash", que o jornalismo se cristalizaria como uma forma social de conhecimento. No entanto, Park não teria condições de fazer tal distinção entre notícia e reportagem no momento em que realizava seus estudos. Conde (2008, p. 25) ressalva que a caracterização parkiana das notícias como forma elementar de conhecimento exclui formas posteriores de jornalismo, como o investigativo e outras formas interpretativas. Em uma das poucas menções que faz a esse tipo de texto, Park sintetiza a reportagem como "algo que tenha interesse humano" (PARK, 2008, p. 60).

Cabe ressaltar, ainda, que a visão de Park, em certa medida, remete a uma noção de objetividade jornalística que deve ser relativizada. 0 amadurecimento do jornalismo enquanto atividade profissional (ação social racional conforme finalidades e valores) levará, mais tarde, a uma visão construcionista do relato jornalístico. Nessa via, passa-se de uma concepção de jornalismo como forma de conhecimento social, como propunha Park, para uma compreensão do jornalismo enquanto instituição socialmente legitimada para produzir conhecimento acerca da realidade cotidiana. Desenvolvendo rotinas para a produção de um discurso escrito "para dizer a verdade", como destaca Miquel Alsina, os jornais estabeleceram um contrato pragmático fiduciário com seus leitores, "um produto histórico da institucionalização e da legitimação do papel do jornalista" (ALSINA, 2009, p. 48). Se a notícia é uma forma de conhecimento, para o jornalismo fazer saber, é preciso que ele seja crível.

Para sustentar a ideia de que os jornalistas têm um papel socialmente legitimado e institucionalizado para recompilar os acontecimentos e dar-lhes sentido, Alsina apoia-se nas bases epistemológicas de Berger e Luckman (2002) sobre a construção social da realidade. Na visão dos autores, não existe apenas uma, mas muitas realidades. Porém, há 
uma que se impõe como sendo a própria realidade: a da vida cotidiana. Esta é objetivada e interpretada a partir de uma série de processos de interação social, pelos quais geramos tipificações que intermedeiam nossas relações com os sujeitos, a forma como vemos o outro e também a nós mesmos. Esses processos interacionais e de tipificação não ocorrem apenas face a face, mas, também, por meio da linguagem. Quanto mais afastados do "aqui e agora" da realidade da vida cotidiana da qual tomamos nossas referências, mais a linguagem atua como "tradutora" de diferentes realidades, estabelecendo pontes entre diferentes zonas dentro da realidade da vida cotidiana para integrá-las em uma totalidade dotada de sentido. Como resultado, a linguagem é capaz de "tornar presente" uma grande variedade de objetos que estão espacial, temporal e socialmente ausentes do aqui e agora (BERGER; LUCKMAN, 2002, p. 59-60).

Dito de outro modo, a linguagem constrói representações simbólicas. Como lembram Berger e Luckman, a religião, a filosofia, a arte e a ciência são sistemas de símbolos historicamente mais importantes no que se refere à transcendência de outros mundos por meio da linguagem. Ocorre que, ao longo do século XX, o jornalismo também adquiriu protagonismo na representação simbólica da realidade, a ponto de converter-se em uma instituição que, nascida para atender às demandas comunicativas da sociedade, tem como especificidade a construção de relatos sobre a realidade pública relevante.

$\mathrm{Na}$ "história natural da imprensa" concebida por Park, o autor considerava os jornais do início do século XX como aqueles que sobreviveram às condições da vida moderna (PARK, 2008a, p. 33). Estamos agora diante de transformações igualmente "rápidas e drásticas", o que nos impõe que perguntemos que jornalismo sobreviverá nas condições da vida "pós-moderna". Daniel Bell (1976), um dos primeiros sociólogos a interpretar esse novo modelo de sociedade, argumentava que a informação e o conhecimento teriam papel central nesse contexto. Sendo assim, o jornalismo, enquanto uma instituição socialmente legitimada para construir conhecimento acerca da realidade cotidiana, teria de exercer papel central no século XXI. Até porque, como aponta Miquel Alsina (2009), informação e conhecimento não são sinônimos. Do mesmo modo que o conteúdo jornalístico não deve ser confundido com outros conteúdos veiculados nos meios de comunicação.

Alinhadas, a concepção do jornalismo como ação social racional (conforme os fins e conforme os valores), e a perspectiva do jornalismo como instituição socialmente autorizadaa a produzir conhecimento sobre a realidade cotidiana, por meio de relatos de acontecimentos públicos e relevantes(ou seja, através de conteúdos de interesse público), dariam 
escopo a um novo paradigma: "paradigma do conhecimento". Ainda que assim nomeado de forma provisória, esse novo modelo se constituiria como um diferencial para o jornalismo do século XXI

Enquanto ação social racional, um jornalismo que não produz conhecimento não tem função social a cumprir, o que o levaria a perder o status de instituição constitutiva da estrutura social. Um padrão centrado no potencial de conhecimento do jornalismo, que preserve os valores que lhe deram legitimidade no século $\mathrm{XX}$, tem objetivos a cumprir no século XXI.

\section{Considerações finais}

Propôs-se, neste texto, uma alternativa de abordagem para os estudos do Jornalismo. Dadas as limitações de espaço e a imaturidade da proposta, que carece de maior desenvolvimento, elegeu-se um aspecto apenas dentre as amplas possibilidades abertas pela tipologia weberiana das ações sociais - aquela que nos permite avançar na periodização de Brin, Charron e Bonville (2004) quanto aos modelos historicamente experimentados pelo jornalismo. Aos modelos de Transmissão (Sec. XVII), de Opinião (Sec. XIX), Informação (final do Sec. XIX e primeira metade do Sec. XX) e de Comunicação (final do Sec. XX), que resultam da aplicação do conceito de tipos ideais, estamos propondo uma concepção/modelo que, se adotada, pode significar a revitalização de uma instituição em crise - um jornalismo de conhecimento. Centrado na reportagem interpretativa e analítica, e ancorado nos valores próprios da profissão (como dever de verdade, pluralidade e interesse público, entre outros), poderia cumprir com mais relevância e qualidade a sua finalidade social.

A partir da mesma base conceitual e metodológica, ainda uma variedade de outras questões relativas aos mais diversos aspectos do jornalismo podem ser problematizadas e desenvolvidas. Este ensaio limita-se a um primeiro exercício de compreensão. 


\section{Referências}

ALSINA, Miquel Rodrigo. A construção da notícia. Petrópolis: Vozes, 2009.

BARBOSA, Maria Ligia de Oliveira; QUINTANEIRO, Tania. Max Weber. In: QUINTANEIRO, Tania; BARBOSA, Maria Ligia de O; OLIVEIRA, Marcia Gardênia de. Um toque de clássicos: Durkheim, Marx e Weber. Belo Horizonte: Editora UFMG, 1999. p. 105-147

BELL, Daniel. The coming of post-industrial society. Basic Books: Nova York, 1999.

BERGER, Peter L.; LUCKMANN, Thomas. A construção social da realidade: tratado de sociologia do conhecimento. Petrópolis: Vozes, 2002.

BRIN, Colette; CHARRON, Jean; BONVILLE, Jean de. Nature et transformation du journalisme - théorie et recherches empiriques. Les Presses de L'Université Laval, Canadá, 2004. Tradução de Márcia Marques e Rogério dy lá Fuente Gonçalves, no prelo.

BUCCI, Eugênio. Sobre ética e imprensa. São Paulo: Companhia das Letras, 2000. CARDOSO, Fernando Henrique; IANNI, Octávio. Homem e sociedade. São Paulo: Cia Editoa Nacional,1973.

CASTELLS, Manuel. A sociedade em rede. 4. ed. São Paulo: Paz e Terra, 2000a.

CONDE, Maria Rosa Berganza. A contribuição de Robert E. Park, o jornalista que se converteu em sociólogo, à teoria da informação. In: BERGER, Christa; MAROCCO, Beatriz (Orgs.). A era glacial do jornalismo: teorias sociais da imprensa, vol. 2. Porto Alegre: Sulina, 2008, pp. 15-32.

COSTA, Caio Túlio. Ética, jornalismo e nova mídia: uma moral provisória. Rio de Janeiro: Jorge Zahar, 2009.

FONSECA, Virginia Pradelina da Silveira. Indústria de Notícias: capitalismo e novas tecnologias no jornalismo contemporâneo. Porto Alegre: Editora da UFRGS, 2008.

GIDDENS, Antony. Sociologia. 6ª ed. Tradução de Ronaldo Cataldo Costa. Porto Alegre: Penso, 2012.

KUSCHIK, Murilo. Weber e a sua relação com a comunicação. In: BERGER, Christa;

MACHADO, Elias. O pioneirismo de Robert E. Park na pesquisa em Jornalismo. Revista Estudos em Jornalismo e Mídia. Programa de Pós-Graduação em Jornalismo e Mídia da Universidade Federal de Santa Catarina ,v. 2, n.1, p 23-34, jul. 2005.

MAROCCO, Beatriz (Orgs.). A era glacial do jornalismo: teorias sociais da imprensa. Porto Alegre: Sulina, 2006. p. 23-33

MAROCCO, Beatriz; BERGER, Christa (Orgs.). A era glacial do Jornalismo: teorias sociais da imprensa. Porto Alegre: Sulina, 2006. 
NÉVEU, Érik. Sociologia do jornalismo. São Paulo: Loyola, 2006.

PARK, Robert. A história natural do jornal. In: BERGER, Christa; MAROCCO, Beatriz (Orgs.). A era glacial do jornalismo: teorias sociais da imprensa, vol. 2. Porto Alegre: Sulina, 2008a, p. 33-50.

PARK, Robert. A notícia como forma de conhecimento: um capítulo dentro da sociologia do conhecimento. In: BERGER, Christa; MAROCCO, Beatriz (Orgs.). A era glacial do jornalismo: teorias sociais da imprensa, vol. 2. Porto Alegre: Sulina, 2008, p. 51-70.

PLAISANCE, Patrick Lee. Ética na Comunicação: princípios para uma prática responsável. Porto Alegre: Penso, 2011.

QUINTANEIRO, Tania; BARBOSA, Maria Ligia de O.; OLIVEIRA, Marcia Gardênia de. Um toque de clássicos: Durkheim, Marx e Weber. Belo Horizonte: Editora UFMG, 1999.

RIBEIRO, Paulo Silvino. Sociologia. Disponível em:

$<$ http://www.brasilescola.com/sociologia/estrutura-social.htm $>$. Acesso em 01/09/2015.

SCHUDSON, Michael. Descobrindo a notícias: uma história social dos jornais nos Estados Unidos. Petrópolis: Vozes, 2010.

SPONHOLZ, Liriam. Jornalismo, conhecimento e objetividade: além do espelho e das construções. Florianópolis: Insular, 2009.

WEBER, Max. Economia e Sociedade: fundamentos da sociologia compreensiva. 4. ed. Brasília: UnB, 2014.

WEBER, Max. Sociologia da imprensa: um programa de pesquisa. In: BERGER, Christa;

MAROCCO, Beatriz (Orgs.). A era glacial do jornalismo: teorias sociais da imprensa. Porto Alegre: Sulina, 2006, p. 34-44 


\title{
Max Weber's contribution to studies on journalism: a methodological-theoretical essay
}

\begin{abstract}
In this article, our goal is to discuss the relevance of Max Webers's concepts and his comprehensive methodology to journalism studies as a constituent institution of the social structure. For this, in the first instance, we take back the concept of social action and its typology, for, afterwards, to discuss the possibility of conceiving journalism as a rational social action according to purposes and according to values. From this discussion, we propose a new paradigm to study journalism that we are calling, even provisionally, as "knowledge's journalism".
\end{abstract}

\section{Keywords}

Journalism. Rational social action. Max Weber. Knowledge's journalism.

Recebido em 14/09/2015

Aceito em 24/11/2015 